\title{
The target cell response to cytokines governs the autoreactive $T$ cell repertoire in the pancreas of NOD mice
}

\author{
M. Hultcrantz • S. Jacobson • N. J. Hill • \\ P. Santamaria $\cdot$ M. Flodström-Tullberg
}

Received: 4 July 2008 / Accepted: 5 October 2008 / Published online: 25 November 2008

(C) Springer-Verlag 2008

\begin{abstract}
Aims/hypothesis The pancreatic beta cell response to cytokines is crucial for the development of type 1 diabetes in the NOD mouse. For example, beta cell production of suppressor of cytokine signalling-1 (SOCS-1) protects against diabetes. This finding and other recent studies indicated that cytokine-stressed beta cells might contribute to disease progression by affecting the pancreatic lymphocyte infiltrate. The aim of this study was to provide insight into how the beta cell influences the pancreas-infiltrating T cell repertoire. Methods Lymphocytes isolated from Socs 1-transgenic (tg) and non-tg NOD mice were analysed by flow cytometry. mRNA and protein levels in pancreatic islets were measured by real-time PCR and immunofluorescence analysis, respectively.
\end{abstract}

Electronic supplementary material The online version of this article (doi:10.1007/s00125-008-1193-7) contains supplementary material, which is available to authorised users.

M. Hultcrantz $\cdot$ S. Jacobson $\cdot$ M. Flodström-Tullberg $(\square)$ Center for Infectious Medicine, Department of Medicine HS, Karolinska Institutet, Karolinska University

Hospital Huddinge, F59,

14186 Stockholm, Sweden

e-mail: malin.flodstrom-tullberg@ki.se

N. J. Hill

Centre for Diabetes and Metabolic Medicine, Institute of Cell and Molecular Sciences,

Barts and the London School of Medicine and Dentistry,

London, UK

P. Santamaria

Julia McFarlane Diabetes Research Center,

Department of Microbiology and Infectious Disease,

University of Calgary Faculty of Medicine,

Calgary, AB, Canada
Results The percentages of regulatory $\mathrm{T}$ cells, total counts and ratios between infiltrating $\mathrm{CD} 8+$ and $\mathrm{CD} 4+\mathrm{T}$ cells, and the expression of killer cell lectin-like receptor subfamily $\mathrm{K}$, member 1 (NKG2D) on CD8+ $\mathrm{T}$ cells did not differ in pancreases from prediabetic Socsl-tg and non-tg NOD mice. However, a striking difference in the percentages of CD8 $+\mathrm{T}$ cells specific for glucose 6-phosphatase catalytic subunit-related protein 206-214 was found, showing that SOCS-1 prevents the accumulation of high percentages of self-reactive $\mathrm{CD} 8+\mathrm{T}$ cells in the pancreas. It was also found that protection from diabetes in Socs 1 -tg NOD mice correlated with a reduced expression of Cxcl10 mRNA in IFN- $\gamma$ treated islets.

Conclusions/interpretation This study highlights an important role for the beta cell in the local regulation of the diabetogenic process. By responding to the pro-inflammatory pancreas milieu it strongly influences the islet-reactive $\mathrm{T}$ cell repertoire in the pancreas.

Keywords Diabetes $\cdot$ Interferon $\cdot$ Non-obese diabetic mouse $\cdot$ Pancreas $\cdot$ Suppressor of cytokine signalling-1
Abbreviations
CFSE 5-(and 6-) carboxyfluorescein diacetate succi- nimidyl ester
CXCL10 chemokine (C-X-C motif) ligand 10
CXCR3 chemokine (C-X-C motif) receptor 3
FOXP3 forkhead box P3
IGRP islet-specific glucose 6-phosphatase catalytic subunit-related protein
NKG2D killer cell lectin-like receptor subfamily K, member 1
PLN pancreatic lymph node
RT real time
SOCS-1 suppressor of cytokine signalling-1 


$\begin{array}{ll}\text { TCR } & \text { T cell receptor } \\ \text { tg } & \text { transgenic } \\ \text { Tregs } & \text { regulatory T cells }\end{array}$

\section{Introduction}

Parenchymal cells may regulate local inflammatory processes. Recent studies have indicated that the target tissue, including the insulin-producing pancreatic beta cell, is an active participant in autoimmunity [1]. The NOD mouse spontaneously develops diabetes as a result of a $\mathrm{T}$ celldependent destruction of beta cells [2]. How the beta cell might affect the diabetogenic process besides providing autoantigens remains largely to be established.

We recently showed that overexpression of Socs 1 specifically in beta cells protects NOD mice from developing diabetes [3]. Suppressor of cytokine signalling-1 (SOCS-1) is a negative regulator of Janus kinase/signal transducer and activator of transcription signalling that inhibits cellular responses to cytokines, including IFN- $\gamma$ [4]. Disease protection in Socs 1 transgenic (tg) NOD mice was not associated with central $\mathrm{T}$ cell tolerance to beta cell antigens or altered insulitis scores in prediabetic animals aged $\leq 14$ weeks. In contrast, adoptive transfer experiments using pancreatic-infiltrating lymphocytes revealed a remarkably low ability of cells isolated from Socs 1 -tg NOD mice to cause diabetes in NOD.Scid recipients (Scid is also known as Prkdc) [3]. These observations raised the question of whether cytokine-exposed beta cells (e.g. following IFN- $\gamma$ release by infiltrating immune cells) might affect the accumulating pancreatic lymphocyte repertoire.

Diabetes modelled in the NOD mouse is in part regulated by the frequencies of regulatory $\mathrm{T}$ cells (Tregs) and specific pathogenic $\mathrm{T}$ cell clones infiltrating the pancreas $[2,5,6]$. Here we took advantage of the Socs 1 -tg NOD mouse model to study whether cytokine-stressed beta cells influence the $\mathrm{T}$ cell repertoire on a local level.

\section{Methods}

Animals and diabetes monitoring The Socs $1-\operatorname{tg}$ and $8.3 \mathrm{~T}$ cell receptor (TCR)-tg NOD mouse models have been described previously $[3,7,8]$. The mice were kept in a specific pathogen-free environment at the Karolinska Institutet. All experiments were conducted in accordance with institutional guidelines and approved by the local ethics committees. Diabetes development was followed by measuring venous blood glucose concentrations under non-fasting conditions using Glucometer Elite strips (Bayer, Stockholm, Sweden). Mice were considered diabetic after two consecu- tive measurements of blood glucose $>13.0 \mathrm{mmol} / \mathrm{l}$, and onset of diabetes was dated from the first of the sequential measurements.

Adoptive transfers Splenocytes from non-diabetic 5- to 7week-old 8.3 TCR-tg NOD mice were harvested and adherent cells were removed by a $1 \mathrm{~h}$ incubation in Petri dishes. The cells were stained with $5 \mu \mathrm{mol} / \mathrm{l}$ 5-(and 6-) carboxyfluorescein diacetate succinimidyl ester (CFSE) (Sigma, Stockholm, Sweden) and injected i.v.

Islet and lymphocyte isolation Islets were isolated from 6to 7-week-old mice in order to retrieve islets that did not have significant numbers of mononuclear infiltrates or significant beta cell destruction. The islets were cultured for 6-7 days before experiments were initiated, as mononuclear cells surrounding the islets are released during this preculture period [7]. The islets were then treated with IFN$\gamma(1,000 \mathrm{U} / \mathrm{ml}$; Calbiochem, distributed by VWR International, Stockholm, Sweden) [9] for $6 \mathrm{~h}$ (real time [RT] PCR) or $24 \mathrm{~h}$ (confocal microscopy). Pancreatic-infiltrating lymphocytes were isolated from 16- to 18 -week-old mice. In order to remove circulating blood, animals were perfused (with PBS) prior to pancreas retrieval. Total lymphocytes were isolated from pancreases digested with collagenase $\mathrm{P}$ (Roche, Stockholm, Sweden) using Lymphoprep (Fresenius Kabi, Uppsala, Sweden) or total T cells were isolated using magnetic cell sorting (MACS) with positive selection of CD90 (Miltenyi Biotec, distributed by Fisher Scientific, Västra Frölunda, Sweden), according to the manufacturers' instructions.

Flow cytometry Following incubation with antibodies to CD16/CD32 cells were stained with anti-NKG2D or IgG isotype control (FITC-labelled) (BioLegend, distributed by Nordic Biosite, Täby, Sweden), anti-CD8a (allophycocyanin [APC]-labelled), anti-CD4 (APC-labelled) (BD Pharmingen, Stockholm, Sweden) and/or tetramers NRPV7 and tumour-derived H-2Kd-binding peptide (TUM), as a negative control (phycoerythin [PE]-labelled) [6]. Intracellular staining with antibodies against forkhead box P3 (FOXP3) and $\mathrm{IgG} 2 \mathrm{a}$ isotype control (PE-labelled) were performed using a FOXP3 Buffer Set (eBioscience, San Diego, CA, USA). Samples were analysed using a FACSCalibur Instrument and CellQuest (BD Pharmingen, Stockholm, Sweden) or FlowJo software (Tree Star, Olten, Switzerland).

RNA isolation and RT-PCR Total RNA was isolated and cDNA synthesised as described [10]. RT-PCR analyses were run with TaqMan Gene Expression assays (Applied Biosystems, Stockholm, Sweden). The mRNA expression level of $\mathrm{Cxcl10}$ was normalised against the mRNA expression level of the housekeeping gene Gapdh. 
Fluorescent staining and confocal microscopy Islets were fixed in formalin, embedded in paraffin and cut in $4 \mu \mathrm{m}$ thick sections. After rehydration the sections were boiled for $5 \mathrm{~min}$ in citrate buffer $(0.01 \mathrm{mmol} / \mathrm{l}, \mathrm{pH} 6)$, followed by incubation in avidin and biotin block (Vector Laboratories, distributed by Immunkemi F\&D AB, Järfälla, Sweden) for $15 \mathrm{~min}$ each. The sections were then incubated in PBSsaponin containing $0.1 \%$ (wt/vol.) BSA-c (an acetylated and partly linearised form of BSA with an increased net negative charge; Aurion, distributed by SMS gruppen, Hørsholm, Denmark) for $30 \mathrm{~min}$. Sections were incubated with a primary antibody against chemokine (C-X-C motif) ligand 10 (CXCL10) (R\&D Systems, Abingdon, UK) overnight followed by the secondary biotinylated antibody (donkey anti-goat; Jackson ImmunoResearch, Suffolk, UK) and the streptavidin-conjugated fluorophore Alexa Fluor 549 (Molecular Probes, Stockholm, Sweden) in the dark. Thereafter the sections were incubated in the primary antibody to insulin (polyclonal anti-swine insulin; Dako Cytomation, Stockholm, Sweden) for 2 h $30 \mathrm{~min}$, followed by biotinylated anti-guinea pig IgG (Vector Laboratories) and streptavidin-conjugated Alexa Fluor 488 (Molecular Probes) as above. The nuclei were visualised using mounting medium containing DAPI (Vectashield, Vector Laboratories). For evaluation, a Leica confocal scanner TCS SP II, coupled to a Leica DMR microscope was used.

Statistical analysis Statistical analyses were performed using GraphPad Prism version 4 software. Differences in diabetes incidence were determined using Kaplan-Meier life-table analysis. RT-PCR data were analysed using a Kruskal-Wallis test (non-parametric ANOVA). Comparisons of $\mathrm{T}$ cell populations in the pancreas were performed using a Mann-Whitney test and the frequencies of chemokine (C-X-C motif) receptor 3 (CXCR3) with a paired $t$ test. Bar graphs represent means $\pm \mathrm{SD}$.

\section{Results}

SOCS1 production protects from diabetes and changes the islet cell response to IFN- $\gamma$ As the incidence of diabetes in the NOD mouse may vary between different mouse colonies and animal facilities, we first confirmed the protection from diabetes in Socs 1 -tg NOD mice from the colony bred at the Karolinska Institutet (Fig. 1a [3]). To determine the magnitude of protection that islet production of SOCS-1 provides against IFN- $\gamma$ we next studied the expression of Cxcl10, a gene encoding an IFN-inducible chemokine produced in the pancreas during diabetes development ([11, 12], M. Hultcrantz and M. FlodströmTullberg, unpublished observation). The expression of
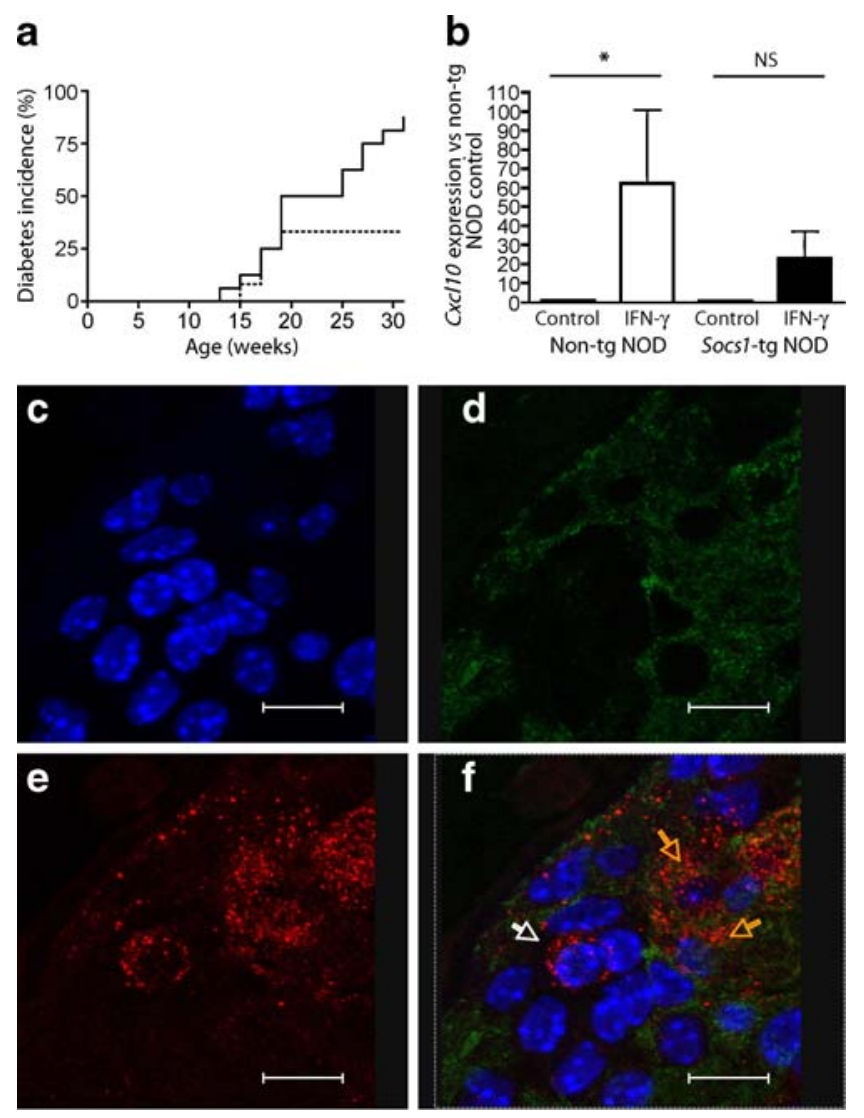

Fig. 1 Reduced diabetes incidence and impaired islet IFN- $\gamma$ response in Socs 1 -tg NOD mice. a Diabetes incidence was monitored in Socs 1tg NOD mice (dotted line; $n=10$ ) and non-tg NOD mice (solid line; $n=13$ ). A significant reduction in diabetes incidence was seen in Socs 1 -tg mice, $p<0.05$, Kaplan-Meier life-table analysis. b Islets from Socs $1-\operatorname{tg}(n=3)$ and non-tg NOD $(n=3)$ mice were treated for $6 \mathrm{~h}$ with IFN- $\gamma$ or left untreated. The expression levels of Cxcl10 mRNA were measured with RT-PCR and normalised to the mRNA expression levels of the housekeeping gene Gapdh and presented as means \pm SD. ${ }^{*} p<0.05$, Kruskal-Wallis test (non-parametric ANOVA). c-f Islets were treated for $24 \mathrm{~h}$ with IFN- $\gamma$, fixed and stained for nuclei (c, blue), insulin (d, green) and CXCL10 (e, red), as described in Methods. The orange arrows in the merged picture (f) show examples of double-positive cells (insulin and CXCL10) and the white arrow shows a cell single stained for CXCL10. Scale bar, $10 \mu \mathrm{m}$

Cxcl10 was significantly upregulated in IFN- $\gamma$-treated islets from non-tg NOD mice, while the induced expression was lower and not significant in islets from Socs 1 -tg NOD mice (Fig. 1b). In agreement with a perturbed, yet notable expression of Cxcl10 in islets from SOCS-1-tg mice, confocal microscopy showed that the production of CXCL10 was not completely blocked in Socs 1 -tg beta cells. This analysis also revealed that only few non-beta cells produce CXCL10 following IFN- $\gamma$ treatment (Fig. 1c$\mathrm{f}$, and data not shown).

No difference in major T cell populations among lymphocytes infiltrating the Socs1-tg NOD pancreas Insulitis scores in Socs 1 -tg NOD mice are comparable to those of 
non-tg NOD mice up to the age of 14 weeks [3]. Adoptive transfer studies using lymphocytes isolated from the pancreases of prediabetic (16- to 18-week-old) mice suggested that the composition of infiltrating lymphocytes might differ between Socs 1 -tg and non-tg NOD mice [3]. Based upon these observations, we set out to characterise the infiltrating $\mathrm{T}$ cell pool in non-diabetic 16- to 18 -weekold Socs 1 -tg and non-tg mice. No difference in the total counts of CD8+ and CD4+ T cells (Electronic supplementary material [ESM] Fig. 1a,b) or in the ratio of CD4+ to CD8+ T cells (ESM Fig. 1c) was found.

Cell-surface expression of NKG2D on CD8 $+\mathrm{T}$ cells is important for diabetes development in the NOD mouse [13]. Islets from NOD mice produce IL-15 [14], a cytokine that induces cell-surface expression of NKG2D on CD8+ T cells [15]. As SOCS-1 reduces $I l 15$ mRNA expression by cytokine-stimulated islets in vitro [16], we postulated that the environment in the Socsl-tg NOD pancreas could be less prone to induce cell-surface expression of NKG2D on infiltrating CD8 $+\mathrm{T}$ cells. However, the frequency of $\mathrm{NKG} 2 \mathrm{D}+$ cells within the CD8+ T cell population was the same in Socs 1-tg and non-tg NOD mice (ESM Fig. 1d).

Tregs play a critical role in delaying autoimmunity in the NOD mouse [5] and target-T cell interactions may promote local generation of Tregs [17]. To investigate whether beta cells might affect the numbers of infiltrating Tregs, and if the lower incidence of diabetes in Socs 1 -tg NOD mice correlated with an increased pool of Tregs, we next studied FOXP3-producing CD4 $+\mathrm{T}$ cells with a known regulatory phenotype [18]. First, we looked at the absolute numbers of FOXP3 + cells infiltrating the Socs 1 -tg $(n=10)$ and non-tg $(n=9)$ NOD pancreas. Similar counts of cells were obtained from the two groups of mice (not shown). We next assessed the percentage of CD4+ $\mathrm{T}$ cells producing FOXP3, but found no differences (ESM Fig. 1e).

Lower frequency of self-reactive $T$ cells in pancreas, pancreatic lymph nodes (PLNS) and peripheral blood of Socs1-tg NOD mice The risk of diabetes development correlates with the frequency of islet-specific $\mathrm{T}$ cells in the peripheral blood and pancreas of NOD mice $[6,19]$. Islet- specific glucose 6-phosphatase catalytic subunit-related protein (IGRP) 206-214-specific CD8+ T cells, identified using $\mathrm{H}-2 \mathrm{~K}^{\mathrm{d}}$ tetramers complexed with the high-affinity NRPV7 mimetic peptide, become particularly prominent during the weeks just before diabetes onset $[6,20,21]$. Here we observed a striking difference in the percentage of IGRP206-214-specific cells within the CD8+ T cell population infiltrating the pancreas of non-diabetic Socs 1 -tg and non-tg NOD mice aged 16-18 weeks (Fig. 2). The percentage of IGRP-specific CD8+ T cells was also lower in PLNs and peripheral blood of Socs 1 -tg NOD mice (Fig. 2). The relevance of SOCS-1 in preventing beta cell damage caused by $\mathrm{T}$ cells with this specificity was shown by protection from diabetes in Socs 1 -tg mice crossed with 8.3 TCR-tg NOD mice harbouring $\mathrm{T}$ cells recognising the 206-214 epitope within the IGRP protein (Fig. 3a, [16]).

We next evaluated whether a lower percentage of IGRP206-214-specific $T$ cells could be a result of a decreased priming of $\mathrm{T}$ cells in the PLNs. However, transfers of splenocytes from young 8.3 TCR-tg NOD mice suggested that $\mathrm{T}$ cell priming was not altered in the PLNs of Socs 1 -tg NOD mice (Fig. 3b).

Following activation in the lymph node, recruitment of activated $\mathrm{T}$ cells to inflamed tissue is dependent on the production of chemokines in the tissue and chemokine receptors on the activated $\mathrm{T}$ cell. As the recruitment of isletspecific T cells may be influenced by pancreatic CXCL10 production and CXCR3 cell-surface expression on T cells $[11,12]$ (see also Fig. 1b) we next studied cell-surface expression of CXCR3 on total CD8+ T cells and NRPV7+ $\mathrm{CD} 8+\mathrm{T}$ cells in the pancreas, PLNs and peripheral blood of non-tg and Socs1-tg NOD mice. Although the vast majority of $\mathrm{T}$ cells present in pancreases are CXCR3+ (Fig. 3e), there was a striking difference in the percentage of CXCR3 + cells between total CD8 $+\mathrm{T}$ cells and the NRPV7 + CD $8+\mathrm{T}$ cells in PLN and blood (Fig. 3c,d). While about $40-80 \%$ of the NRPV7+CD8+ cells were CXCR3 3 only $10-20 \%$ of the total CD $8+\mathrm{T}$ cells were CXCR3+, indicating that the NRPV7+CD8+ T cells are more likely to be recruited by an increase in the islet production of CXCL10.
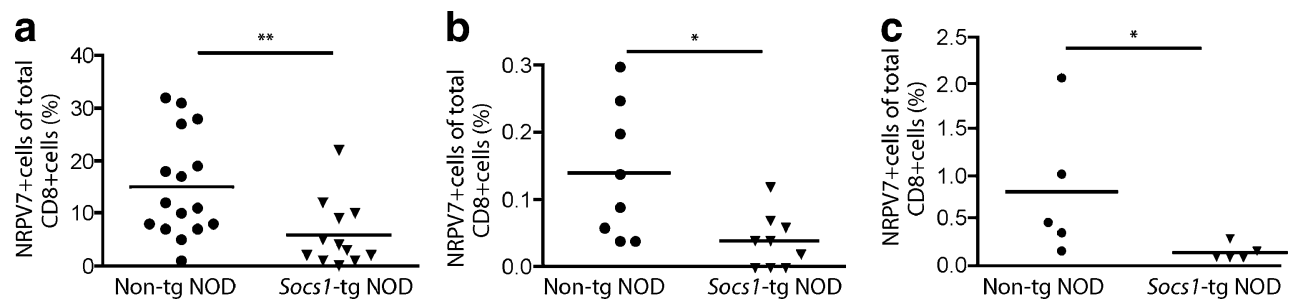

Fig. 2 SOCS-1 production reduces the frequencies of IGRP-specific CD8+ T cells in the pancreas (a), PLNs (b) and peripheral blood (c) of NOD mice. The frequencies of NRPV7 tetramer-positive CD8+ T cells

were assessed in pancreases, PLNs and blood of 16- to 18-week-old mice using flow cytometry. Horizontal bars indicate the mean values. ${ }^{*} p<0.05,{ }^{* *} p<0.01$ (Mann-Whitney test) 

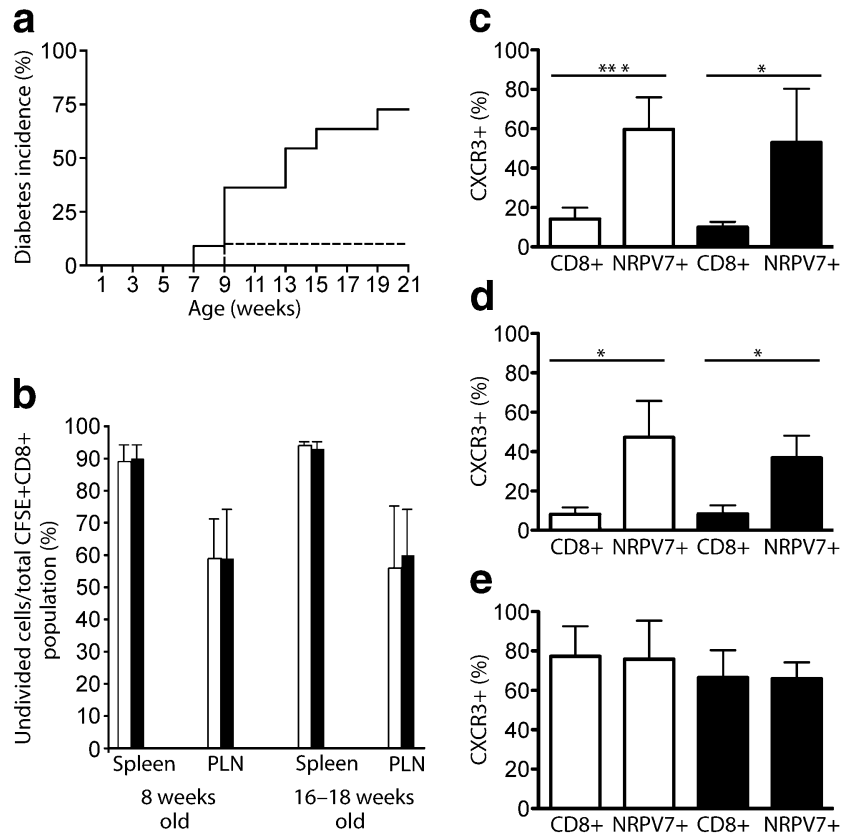

Fig. 3 IGRP206-214-specific CD8+ T cells do not have an altered proliferation in PLN, but are frequently positive for the chemokine receptor CXCR3. a Diabetes incidence was monitored in 8.3 TCR$\operatorname{tg} \times$ Socs 1 -tg NOD mice (dotted line; $n=10$ ) and 8.3 TCR-tg NOD mice (solid line; $n=11$ ). A significant reduction in diabetes incidence was seen in 8.3 TCR-tg $\times$ Socs 1 -tg mice compared with 8.3 TCR-tg NOD mice, $p<0.01$, Kaplan-Meier life-table analysis. b CFSElabelled splenocytes from young 8.3 TCR-tg NOD mice were transferred to Socs 1 -tg NOD mice (black bars; $n=5$ for each group) and non-tg NOD mice (white bars; $n=5$ for each group) aged 8 weeks or 16-18 weeks. The frequencies of undivided CFSE-labelled CD8+ cells were analysed by flow cytometry in PLNs and spleens on day 3 after transfer. Data are presented as means \pm SD. CD8+ and NRPV7+ CD8+ T cells from blood (c), PLN (d) and pancreas (e) from 16- to 19-week-old Socs 1 -tg NOD mice (black bars; $n=3-5$ ) and non-tg NOD mice (white bars; $n=4-6$ ) were analysed for their cell-surface expression of CXCR3 by flow cytometry. Data are presented as means \pm SD. $* p<0.05, * * * p<0.001$ (paired $t$ test)

\section{Discussion}

Immune reactions to self are regulated by central and peripheral tolerance mechanisms [22, 23]. Recent studies have indicated that the target organ itself may provide an additional level of control [1]. The present study suggests that the beta cell in the NOD mouse actively contributes to the pathogenic process by modulating the autoreactive $\mathrm{T}$ cell repertoire in the pancreas.

In this study the Socs 1-tg NOD mouse model was used to investigate how cytokine-stressed beta cells contribute to the diabetogenic process. Production of SOCS-1 by beta cells protects NOD mice [3] and TCR-tg 8.3 NOD mice ([16], and present study) from diabetes. SOCS-1 efficiently blocks the biological effects of IFN- $\gamma[3,24]$, but also other cytokines such as IFN- $\alpha$, IL-4 and IL-6 [4, 7], which may also influence diabetes development. IFN- $\gamma$ together with the cytokine IL-1 causes beta cell damage in vitro [25]. SOCS-3, another member of the SOCS family that has some functional overlap with SOCS-1, has been shown to block the response to IL-1 [26]. This indicates that SOCS-1 may also provide protection from the actions of IL-1.

Our adoptive transfer studies using splenocytes from 8.3 TCR-tg NOD (Fig. 3b) and BDC2.5-tg NOD (M. FlodströmTullberg, unpublished observation) showed that $\mathrm{T}$ cell priming in the PLN occurs normally in the Socs $1-\operatorname{tg}$ NOD mouse. In addition, our studies suggest that beta cells exposed to pro-inflammatory cytokines like IFN- $\gamma$ do not have a major influence on the overall recruitment of lymphocytes to the pancreas in the NOD mouse ([3], and present study). This is further supported by previous studies in double transgenic 8.3 TCR-tg $\times$ Socs 1 -tg NOD mice [16], and supports a notion that autoreactive $\mathrm{T}$ cell clones are influenced locally by indirect or direct interactions with target cells.

It was recently shown that effector CD4+ T cells convert into FOXP3+ Tregs upon encounter with neurons, thereby suppressing experimental autoimmune encephalitis [17]. Although CD4+ T cells are present in high numbers in the Socs 1 -tg NOD pancreas no signs of increased numbers of CD4+FOXP3+ cells were observed in the pancreas (ESM Fig. 1e) or PLNs (not shown). A local regulation of NKG2D cell-surface expression on infiltrating CD8+ T cells was also not supported by our findings, suggesting that islet cell production of IL-15 [13, 14, 16] may not have a potent effect on the recruited CD8 $+\mathrm{T}$ cell population.

The present study shows that the percentage of IGRP206-214-specific CD8+ T cells is dramatically lower in the Socs 1 -tg NOD pancreas compared with non-tg NOD pancreas. We also observed a lower frequency of these cells in PLNs and peripheral blood of Socs 1-tg mice. This is in agreement with previous studies showing that the frequency of IGRP206-214-specific CD8+ $\mathrm{T}$ cells in the blood reflects the frequency in the pancreas and can predict disease development in NOD mice [6, 19].

The observation that the frequency of IGRP206-214specific CD8 + T cells is reduced in the pancreas of Socs $1-\mathrm{tg}$ mice, together with the finding that the total CD8+ T cell counts did not differ, clearly suggests that beta cells have a local effect on islet-specific $\mathrm{T}$ cell clones. Several, nonmutually exclusive, mechanisms may contribute to this. Cytokines may directly cause islet cell damage and thereby the release of antigens, supporting an efficient restimulation of islet-specific $\mathrm{T}$ cell clones upon their arrival in the pancreas. Importantly, SOCS-1 prevents the cytokineinduced production of molecules such as MHC class I [16] and CD40 (M. Hultcrantz and M. Flodström-Tullberg, unpublished observation), suggesting that the pro-inflammatory milieu in the NOD pancreas normally enhances CD8+ T cell recognition of beta cells and increases beta cell susceptibility to damage induced via CD40 ligand [27]. The 
former mechanism is supported by a study demonstrating that a block in the cell-surface expression of MHC class I specifically in beta cells impairs the accumulation of autoreactive $\mathrm{CD} 8+\mathrm{T}$ cells in islets without affecting priming in the PLNs [28]. Furthermore, exogenously added IGRP peptide has been shown to increase the recognition and specific killing of Socs 1-expressing islets [29].

Although no difference was seen in the overall numbers of pancreas-infiltrating CD4+ and CD8+ T cells it cannot be excluded that beta cell production of chemokines locally affects the specific recruitment and/or stimulates the retention of islet-specific $\mathrm{T}$ cells after their initial priming in the PLN. Indeed, we observed a lower expression of Cxcl10 by IFN-exposed Socs 1 -tg islet cells (Fig. 1b), a gene encoding a chemokine shown to be of importance in other models of type 1 diabetes $[11,12,30]$. We also found that the receptor CXCR3 is present more frequently on NRPV7+CD8 $+\mathrm{T}$ cells than on the bulk CD8 $+\mathrm{T}$ cells in PLNs and peripheral blood (Fig. 3c,d), suggesting a preferential recruitment of NRPV7+CD8+ T cells to the inflamed pancreas. Finally, our preliminary transfer experiments have demonstrated a reduced retention of CFSE-labelled CD8+ T cells from 8.3 TCR-tg mice in pancreases of Socs 1 -tg NOD mice compared non-tg NOD mice (M. Hultcrantz and M. Flodström-Tullberg, unpublished observation).

A long prediabetic period with an innocuous insulitis such as that observed in the NOD mouse may not be a typical hallmark of type 1 diabetes in humans. However, insulitis has been observed in non-diabetic organ donors positive for three or four autoantibodies [31]. Moreover, lymphocytes are often found in or around islets of newly diagnosed patients (e.g. [32-35]), indicating that their recruitment is crucial for disease development. CXCL10 is an interesting candidate chemokine since newly diagnosed type 1 diabetes patients have elevated serum levels of CXCL10 [36], and human T cells expressing CXCR3 have been shown to home to the islets in NOD.Scid mice [37]. More recent data from a patient with newly onset type 1 diabetes showed CXCL10 production in islets and CXCR3 expression on pancreas-infiltrating lymphocytes [38]. That the percentage of IGRP-specific T cells was lower in the Socs 1 -tg NOD mouse pancreas is also of potential interest for human type 1 diabetes, as IGRP-specific $\mathrm{T}$ cell clones have been identified in type 1 diabetes patients [39, 40]. Prevention of the migration of these cells and other potentially autoreactive $\mathrm{T}$ cells to the islets by a block in CXCL10 production may be a therapeutic measure worth trying in individuals with a high risk of developing type 1 diabetes [41].

In summary, the present study suggests that the beta cell response to cytokines is essential for the accumulation of pathogenic $\mathrm{T}$ cells and the progression from insulitis to diabetes in the NOD mouse. This highlights an additional level of regulation that is present in non-lymphoid tissue and dependent on the target cell itself.

Acknowledgements The authors thank N. Sarvetnick, The Scripps Research Institute, La Jolla, CA, USA, for fruitful discussions. We also thank M. Hühn, Karolinska Institutet, Stockholm, Sweden, for critical reading of the manuscript and A. Hoffman, Karolinska Institutet, for excellent technical assistance with the confocal microscopy. This work was supported by a Marie Curie International Reintegration Grant (M. Flodström-Tullberg), a transitional award from the Juvenile Diabetes Research Foundation (M. FlodströmTullberg), the European Foundation for the Study of Diabetes (M. Flodström-Tullberg), the Swedish Foundation for Strategic Research (M. Flodström-Tullberg), and the Swedish Research Council (M. Flodström-Tullberg). P. Santamaria is supported by the Canadian Institutes of Health Research, and is a Scientist of the Alberta Heritage Foundation for Medical Research. Some parts of this work were presented as an abstract at the 9th International Congress of the Immunology of Diabetes Society and American Diabetes Association Research Symposium (Miami, 2007) and in a thesis by M. Hultcrantz, Department of Medicine, Karolinska Institutet, Stockholm (Interferons in antiviral defense and autoimmunity: focus on type 1 diabetes) defended in 2008 at the Karolinska Institutet, Sweden.

Duality of interest The authors declare that there is no duality of interest associated with this manuscript.

\section{References}

1. Hill NJ, Hultcrantz M, Sarvetnick N, Flodstrom-Tullberg M (2007) The target tissue in autoimmunity - an influential niche. Eur J Immunol 37:589-597

2. Anderson MS, Bluestone JA (2005) The NOD mouse: a model of immune dysregulation. Annu Rev Immunol 23:447-485

3. Flodstrom-Tullberg M, Yadav D, Hagerkvist R et al (2003) Target cell expression of suppressor of cytokine signaling-1 prevents diabetes in the NOD mouse. Diabetes 52:2696-2700

4. Yoshimura A, Naka T, Kubo M (2007) SOCS proteins, cytokine signalling and immune regulation. Nat Rev Immunol 7:454-465

5. Tritt M, Sgouroudis E, d'Hennezel E, Albanese A, Piccirillo CA (2008) Functional waning of naturally-occurring CD4+ regulatory $\mathrm{T}$ cells contributes to the onset of autoimmune diabetes. Diabetes 57:113-123

6. Trudeau JD, Kelly-Smith C, Verchere CB et al (2003) Prediction of spontaneous autoimmune diabetes in NOD mice by quantification of autoreactive $\mathrm{T}$ cells in peripheral blood. J Clin Invest 111:217-223

7. Flodstrom M, Maday A, Balakrishna D, Cleary MM, Yoshimura A, Sarvetnick N (2002) Target cell defense prevents the development of diabetes after viral infection. Nat Immunol 3:373-382

8. Verdaguer J, Schmidt D, Amrani A, Anderson B, Averill N, Santamaria P (1997) Spontaneous autoimmune diabetes in monoclonal T cell nonobese diabetic mice. J Exp Med 186:1663-1676

9. Flodstrom-Tullberg M, Hultcrantz M, Stotland A et al (2005) RNase L and double-stranded RNA-dependent protein kinase exert complementary roles in islet cell defense during coxsackievirus infection. J Immunol 174:1171-1177

10. Hultcrantz M, Huhn MH, Wolf $M$ et al (2007) Interferons induce an antiviral state in human pancreatic islet cells. Virology 367:92-101

11. Frigerio S, Junt T, Lu B et al (2002) Beta cells are responsible for CXCR3-mediated T cell infiltration in insulitis. Nat Med 8:1414 1420 
12. Christen U, von Herrath MG (2004) IP-10 and type 1 diabetes: a question of time and location. Autoimmunity 37:273-282

13. Ogasawara K, Hamerman JA, Ehrlich LR et al (2004) NKG2D blockade prevents autoimmune diabetes in NOD mice. Immunity 20:757-767

14. Cardozo AK, Proost P, Gysemans C, Chen MC, Mathieu C, Eizirik DL (2003) IL-1beta and IFN-gamma induce the expression of diverse chemokines and IL-15 in human and rat pancreatic islet cells, and in islets from pre-diabetic NOD mice. Diabetologia 46:255-266

15. Roberts AI, Lee L, Schwarz E et al (2001) NKG2D receptors induced by IL- 15 costimulate CD28-negative effector CTL in the tissue microenvironment. J Immunol 167:5527-5530

16. Chong MM, Chen Y, Darwiche R et al (2004) Suppressor of cytokine signaling-1 overexpression protects pancreatic beta cells from CD8+ T cell-mediated autoimmune destruction. J Immunol 172:5714-5721

17. Liu Y, Teige I, Birnir B, Issazadeh-Navikas S (2006) Neuronmediated generation of regulatory $\mathrm{T}$ cells from encephalitogenic $\mathrm{T}$ cells suppresses EAE. Nat Med 12:518-525

18. Zheng Y, Rudensky AY (2007) Foxp3 in control of the regulatory T cell lineage. Nat Immunol 8:457-462

19. Wong CP, Stevens R, Long B et al (2007) Identical beta cellspecific $\mathrm{CD} 8(+) \mathrm{T}$ cell clonotypes typically reside in both peripheral blood lymphocyte and pancreatic islets. J Immunol 178:1388-1395

20. Amrani A, Verdaguer J, Serra P, Tafuro S, Tan R, Santamaria P (2000) Progression of autoimmune diabetes driven by avidity maturation of a $\mathrm{T}$ cell population. Nature 406:739-742

21. Lieberman SM, Evans AM, Han B et al (2003) Identification of the beta cell antigen targeted by a prevalent population of pathogenic CD8+ T cells in autoimmune diabetes. Proc Natl Acad Sci U S A 100:8384-8388

22. Gallegos AM, Bevan MJ (2006) Central tolerance: good but imperfect. Immunol Rev 209:290-296

23. Redmond WL, Sherman LA (2005) Peripheral tolerance of CD8 T lymphocytes. Immunity 22:275-284

24. Alexander WS, Starr R, Fenner JE et al (1999) SOCS1 is a critical inhibitor of interferon gamma signaling and prevents the potentially fatal neonatal actions of this cytokine. Cell 98:597608

25. Eizirik DL, Mandrup-Poulsen T (2001) A choice of death-the signal-transduction of immune-mediated beta-cell apoptosis. Diabetologia 44:2115-2133

26. Karlsen AE, Ronn SG, Lindberg K et al (2001) Suppressor of cytokine signaling 3 (SOCS-3) protects beta-cells against interleukin-1beta- and interferon-gamma-mediated toxicity. Proc Natl Acad Sci U S A 98:12191-12196

27. Barbe-Tuana FM, Klein D, Ichii $\mathrm{H}$ et al (2006) CD40-CD40 ligand interaction activates proinflammatory pathways in pancreatic islets. Diabetes 55:2437-2445

28. Yamanouchi J, Verdaguer J, Han B, Amrani A, Serra P, Santamaria P (2003) Cross-priming of diabetogenic T cells dissociated from CTL-induced shedding of beta cell autoantigens. J Immunol 171:6900-6909

29. Dudek NL, Thomas HE, Mariana L et al (2006) Cytotoxic T cells from $\mathrm{T}$ cell receptor transgenic NOD8.3 mice destroy beta-cells via the perforin and Fas pathways. Diabetes 55:2412-2418

30. Barral AM, Thomas HE, Ling EM et al (2006) SOCS-1 protects from virally-induced $\mathrm{CD} 8 \mathrm{~T}$ cell mediated type 1 diabetes. J Autoimmun 27:166-173

31. In't Veld P, Lievens D, de Grijse J et al (2007) Screening for insulitis in adult autoantibody-positive organ donors. Diabetes $56: 2400-2404$

32. Bottazzo GF, Dean BM, McNally JM, MacKay EH, Swift PG, Gamble DR (1985) In situ characterization of autoimmune phenomena and expression of HLA molecules in the pancreas in diabetic insulitis. N Engl J Med 313:353-360

33. Dotta F, Censini S, van Halteren AG et al (2007) Coxsackie B4 virus infection of beta cells and natural killer cell insulitis in recent-onset type 1 diabetic patients. Proc Natl Acad Sci U S A 104:5115-5120

34. Hanninen A, Jalkanen S, Salmi M, Toikkanen S, Nikolakaros G, Simell O (1992) Macrophages, T cell receptor usage, and endothelial cell activation in the pancreas at the onset of insulindependent diabetes mellitus. J Clin Invest 90:1901-1910

35. Somoza N, Vargas F, Roura-Mir C et al (1994) Pancreas in recent onset insulin-dependent diabetes mellitus. Changes in HLA, adhesion molecules and autoantigens, restricted $\mathrm{T}$ cell receptor $\mathrm{V}$ beta usage, and cytokine profile. J Immunol 153:1360-1377

36. Nicoletti F, Conget I, Di Mauro M et al (2002) Serum concentrations of the interferon-gamma-inducible chemokine IP-10/CXCL10 are augmented in both newly diagnosed type I diabetes mellitus patients and subjects at risk of developing the disease. Diabetologia 45: $1107-1110$

37. van Halteren AG, Kardol MJ, Mulder A, Roep BO (2005) Homing of human autoreactive $\mathrm{T}$ cells into pancreatic tissue of NOD-scid mice. Diabetologia 48:75-82

38. Dotta F, Bonato V, Vendrame F et al (2008) Islet inflammation and $\mathrm{T}$ cell autoreactivity in pancreas-draining lymph nodes during recent onset type 1 diabetes. In: TONECA coordination action on the aetiology, pathology and prediction of type 1 diabetes in Europe, Siena, Italy. Available from http://www.unisi.it/eventi/ toneca/abstracts.pdf

39. Jarchum I, Nichol L, Trucco M, Santamaria P, DiLorenzo TP (2008) Identification of novel IGRP epitopes targeted in type 1 diabetes patients. Clin Immunol 127:359-365

40. Unger WW, Pinkse GG, Mulder-van der Kracht S et al (2007) Human clonal CD8 autoreactivity to an IGRP islet epitope shared between mice and men. Ann N Y Acad Sci 1103:192-195

41. Christen U, McGavern DB, Luster AD, von Herrath MG, Oldstone MB (2003) Among CXCR3 chemokines, IFN-gammainducible protein of $10 \mathrm{kDa}$ (CXC chemokine ligand (CXCL) 10) but not monokine induced by IFN-gamma (CXCL9) imprints a pattern for the subsequent development of autoimmune disease. $\mathrm{J}$ Immunol 171:6838-6845 